\title{
8
}
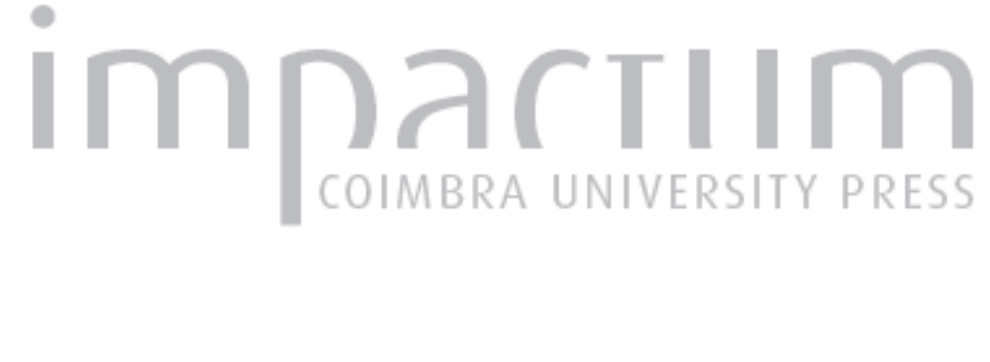

\section{O estudo da história antiga a partir de textos literários: uma proposta teórico- metodológica}

\author{
Autor(es): $\quad$ Sousa, Paulo Ângelo de Meneses
}

Publicado por: Imprensa da Universidade de Coimbra

URL persistente:

URI:http://hdl.handle.net/10316.2/41456

DOI:

DOI:https://doi.org/10.14195/0872-2110_60_4

Accessed : $\quad$ 26-Apr-2023 07:18:05

A navegação consulta e descarregamento dos títulos inseridos nas Bibliotecas Digitais UC Digitalis, UC Pombalina e UC Impactum, pressupõem a aceitação plena e sem reservas dos Termos e Condições de Uso destas Bibliotecas Digitais, disponíveis em https://digitalis.uc.pt/pt-pt/termos.

Conforme exposto nos referidos Termos e Condições de Uso, o descarregamento de títulos de acesso restrito requer uma licença válida de autorização devendo o utilizador aceder ao(s) documento(s) a partir de um endereço de IP da instituição detentora da supramencionada licença.

Ao utilizador é apenas permitido o descarregamento para uso pessoal, pelo que o emprego do(s) título(s) descarregado(s) para outro fim, designadamente comercial, carece de autorização do respetivo autor ou editor da obra.

Na medida em que todas as obras da UC Digitalis se encontram protegidas pelo Código do Direito de Autor e Direitos Conexos e demais legislação aplicável, toda a cópia, parcial ou total, deste documento, nos casos em que é legalmente admitida, deverá conter ou fazer-se acompanhar por este aviso.

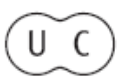


COIMBRA • 2015

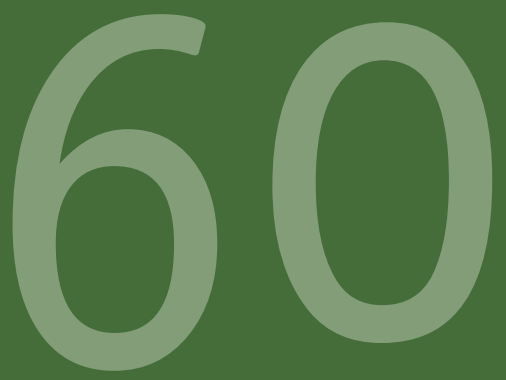

\title{
BOLETIM DE
}

\section{ESTUDOS CLÁSSICOS}

\author{
ASSOCIAÇÃO \\ PORTUGUESA \\ DE ESTUDOS \\ CLÁSSICOS \\ INSTITUTO \\ DE ESTUDOS \\ CLÁSSICOS
}




\title{
0 ESTUDO DA HISTÓRIA ANTIGA A PARTIR DE TEXTOS LITERÁRIOS - UMA PROPOSTA TEÓRICO- -METODOLÓGICA
}

\section{THE STUDY OF ANCIENT HISTORY FROM LITERARY TEXTS - A THEORETICAL AND METHODOLOGICAL APPROACH}

\author{
PAULO ÂNGELO DE MENESES SOUSA ${ }^{1}$ \\ UNIVERSIDADE FEDERAL DO PIAUÍ \\ angeloufpi@ig.com.br
}

Resumo: $\mathrm{O}$ artigo apresenta e discute uma proposta teórico-metodológica desenvolvida no nosso livro didático A História Antiga a partir de textos literários, inédito, elaborado no decorrer de nossa experiência de ensino na disciplina História Antiga do curso de graduação em História da Universidade Federal do Piauí (Brasil), no qual propomos estudar a História Antiga a partir de textos literários, principalmente da Grécia e Roma antigas.

Palavras-chave: História e Literatura, Teoria e metodologia da história, Ensino de História Antiga.

${ }^{1}$ Professor Associado do Departamento de História da Universidade Federal do Piauí (Brasil). Doutor em História Social pela Universidade de São Paulo. 
Abstract: The article presents and discusses a theoretical and methodological approach developed in our textbook Ancient History from literary texts, inedited, elaborated during our teaching experience in Ancient History discipline of the bachelor's degree in History at Federal University of Piauí (Brasil) in which we propose to study Ancient History from literary texts, mainly from ancient Greece and Rome.

Keywords: History and Literature; Theory and methodology of history; Teaching of Ancient History.

Desde a segunda metade do século xx, a ciência histórica tem alargado seus domínios abrindo a possibilidade de se trabalhar com uma grande variedade de fontes e objetos.

Dentro desse campo aberto aos historiadores e pesquisadores, as obras literárias ocupam um lugar importante nas pesquisas históricas enquanto objeto de construção do conhecimento histórico.

No entanto, o interesse dos historiadores pelos textos literários não é um fenômeno recente nos estudos históricos.

Em se tratando da história da antiguidade - marcada pela escassez documental se comparada à abundância das épocas recentes - os textos literários antigos são, desde há muito tempo, um objeto privilegiado de pesquisa tendo em vista que, fora do campo da arqueologia, a maioria dos estudos de História Antiga são estudos de textos, estudos de representações.

Se o interesse dos historiadores pelos textos literários não é algo novo, entretanto, o que assistimos mudar desde a segunda metade do século xx - devido a uma renovação nos estudos literários que veio influenciar os estudos históricos - é essa relação entre os historiadores e os textos literários.

A utilização da literatura enquanto documento histórico traz uma série de dificuldades para os historiadores, exigindo deles uma nova concepção de texto literário bem como a necessidade de se desenvolver novos procedimentos interpretativos. 
Em termos teóricos e metodológicos, já existem diversas tendências dentro dos estudos históricos que buscam romper com os usos tradicionais e "reducionistas" que os historiadores fazem da literatura, apontando novos rumos para a leitura histórica de textos literários.

As principais críticas feitas à utilização que os historiadores fazem da Literatura enquanto documento histórico diz respeito à desconsideração da especificidade da linguagem literária e ao uso da Literatura enquanto documento de realidade. ${ }^{2}$

No primeiro aspecto, critica-se o fato do historiador ter uma visão instrumentalista da linguagem enquadrando as obras literárias dentro de uma concepção geral de documento assim como qualquer outra fonte de pesquisa, não considerando a especificidade própria da linguagem literária. No segundo aspecto, critica-se o fato de o historiador tomar o texto literário como um documento confirmador de uma realidade prévia a ele, ou seja, como um "espelho" da estrutura da sociedade. Nesse tipo de leitura, a habilidade do historiador consistiria, portanto, em extrair os dados da realidade a partir da narrativa literária, pressupondo que a narrativa "autêntica" do fato coincide com ele mesmo.

Considerar o texto literário como "espelho" de uma realidade social exclui a ideia de "representação" com a qual a crítica literária tem pensado as relações entre linguagem literária e realidade social. Nesse sentido, embora a "representação" se refira ao real, no entanto, ela não simplesmente o espelha, mas o reconstrói de uma outra maneira.

\section{A LITERATURA}

A Literatura, para alguns estudiosos, além de ter um grande potencial enquanto documento histórico, por revelar as sensibilidades de uma

\footnotetext{
${ }^{2}$ Cf. Andrade 2000: 65ss.
} 
época, tem sido uma fonte de renovação nos estudos históricos, durante muito tempo cativo de documentos de teor político e econômico.

No entanto, a escolha de objetos "culturais" (inclui-se a arte e a literatura) tem se tornado uma "moda" na atualidade, transformando-se, para outros autores ${ }^{3}$ essa, numa nova ortodoxia nos estudos históricos.

Apesar de nosso estudo se concentrar nos textos literários, é preciso não perder de vista também outros objetos e diferentes abordagens da História Antiga. O que é a arte ${ }^{4}$ Como a arte pode proporcionar ao historiador um conhecimento das sociedades? o ponto em comum entre as várias formas de arte (literatura, música, artes plásticas, etc.) é a "possibilidade de o artista recriar a realidade".

Uma das mais antigas definições da arte é a de Aristóteles: "a arte é imitação (mimese) da realidade”. Palavras para definir a arte: imitação, mentira que revela a verdade, transformação simbólica do mundo, invenção de outra realidade. ${ }^{5}$ Essa criação não é produto do nada, nasce da experiência de vida do artista. O que distingue as formas de arte são suas "maneiras de expressar", no caso da Literatura, é a linguagem oral ou escrita. A linguagem não é algo tão livre, é criação humana e segue alguns parâmetros para se expressar: língua, forma, gêneros, etc.

A arte não expressa a realidade tal qual é, ela recria a realidade, revela uma outra verdade, diferente da verdade do realismo. Os fatos que dão origem à arte perdem sua realidade primeira e adquirem outra. São verdades não medidas pelos padrões factuais (dos fatos); são verdades humanas gerais, que traduzem um sentido de vida, uma experiência de vida. Para alguns autores ${ }^{6}$, a arte fala de verdades

${ }^{3}$ Ribeiro 1994: 7-13.

${ }^{4}$ Sobre esse aspecto, veja-se as reflexões de Bosi: 1986.

${ }^{5}$ Existem outras maneiras de se definir a arte (e a literatura) que não abordaremos aqui; trata-se de um debate complexo e em aberto. Sobre as tentativas de definição de Literatura, ver Cardoso 1999; Todorov 1980.

${ }^{6}$ Nicola 2003: 16. 
universais, atemporais, comum a todos os homens; a arte - e a literatura - estaria, assim, próxima da filosofia.

Os historiadores têm analisado a arte (e a literatura) do ponto de vista materialista ${ }^{7}$, ou seja, entendem que a arte não transcende a realidade cultural que a produziu, mas que a incorpora. A "transformação / invenção" de uma nova realidade que a arte produz, segundo o historiador, não é arbitrária, nasce da vida, da própria experiência, que é temporal (esse é o sentido da historicidade da arte ). A própria linguagem utilizada tem base na cultura - as palavras utilizadas têm seus antecedentes, não há criação do nada.

O estudo da arte (e da literatura) é, para o historiador, o estudo das representações sociais, toca no campo do imaginário das sociedades e o imaginário faz parte do real. Para o historiador, toda arte está inserida no seu tempo, e o estudo de suas formas e expressões permite compreender a sociedade na qual está inserida. No caso dos textos literários antigos escolhidos para análise no nosso livro didático ${ }^{8}$, uma abordagem histórica revelará o conjunto das ideias, dos valores e dos sentimentos que informam a experiência social que podem ser compreendidos através desses textos literários. 0 historiador limita o homem ao seu tempo, mas - para outros - o seu lado atemporal permanece.

\section{A ARTICULAÇÃO ENTRE LITERATURA E SOCIEDADE}

Admitido pelo historiador que a literatura (e a arte) só pode ser compreendida a partir da experiência social e temporal que a gerou, os historiadores, no entanto, seguem caminhos diversos quando se trata de demonstrar como se dá essa articulação da literatura com a sociedade. Para alguns autores (historiadores e teóricos da literatura), as expressões literárias vistas não como fenômeno individual, mas

\footnotetext{
${ }^{7}$ Chalhoub 1998: 7.

${ }^{8}$ Sousa 2010.
} 
coletivo, constituem os chamados gêneros literários (epopeia, tragédia, comédia, etc.). Uma vez institucionalizados, esses gêneros evidenciam os aspectos constitutivos da sociedade a que pertencem. Os gêneros literários são "tipos relativamente estáveis de enunciados” (Bakhtin/ Todorov), eles representam características comuns, em determinada época, das obras tanto no plano formal como nas ideias. Esses gêneros estão relacionados, segundo o historiador, com as épocas e momentos históricos específicos.

No caso do nosso estudo, por exemplo, o gênero da tragédia está relacionado com a implantação dos tribunais de justiça no final da Grécia arcaica e a comédia com a crise social e a corrupção dos costumes no final da Grécia clássica. É importante destacar que, para alguns autores, essas obras nem sempre são determinadas pelos seus momentos históricos (seu aspecto atemporal?), mas, por outro lado, pode-se perceber o início e o fim de um gênero literário situado numa época.

Essa perspectiva de abordar a articulação entre literatura e sociedade a partir da noção de gênero literário tem sido questionada.

A noção de gênero literário, herança da cultura clássica, passou por uma crítica desde os anos 1960. Primeiro, por ser redutora às obras ditas "clássicas", aos padrões clássicos; segundo, por não dar conta da infinidade das manifestações literárias; terceiro, o uso da teoria dos gêneros literários é uma compartimentação operacional, na prática, a experiência literária transcende esses limites. Ainda nessa perspectiva de crítica à noção de gênero literário, uma determinada corrente da antropologia literária considera que as definições e classificações dos gêneros literários raramente permitem construir hipóteses fecundas, sobretudo, a propósito das literaturas tradicionais, sua transmissão e os processos cognitivos que elas põem em jogo.

Embora a nossa escolha se situe ainda a partir da noção de "gênero literário", a nossa proposta, no entanto, é entender esses gêneros enquanto "gêneros do discurso" (segundo Todorov), mas no sentido amplo (os documentos para os historiadores são discursos). Falar em gêneros 
do discurso ao abordarmos textos literários é, para nós, tentar iniciar uma reflexão sobre os caminhos da análise histórica do discurso. Dessa forma, as obras escolhidas situam-se, algumas delas, ainda dentro da teoria clássica dos gêneros ${ }^{9}$, como a epopeia (Homero), tragédia (Ésquilo), comédia (Aristófanes) e a fábula (Fedro); já outras são consideradas por nós também "gêneros literários", como a história (Heródoto), a filosofia (Platão), oratória (Demóstenes) e a teologia (Agostinho).

A proposta desse nosso livro situa-se no campo dos textos literários da Antiguidade Clássica (principalmente da Grécia), mas acreditamos que a reflexão metodológica sobre o estudo da literatura para se compreender uma sociedade pode ser proveitosa para outras áreas da História Antiga. Delimitando nossa proposta, foram escolhidas, em ordem cronológica e didática, formas literárias que consideramos significativas na Antiguidade Clássica, como a Epopeia, Tragédia, História, Comédia, Oratória, Fábulas e os textos filosóficos e teológicos.

Para caracterizar cada forma literária, foram escolhidas algumas obras a partir de um critério de unidade de conteúdo que nos proporciona uma dinâmica de leitura.

Propomos analisar as seguintes obras:

- Epopeia (séc. VIII a.C.)

- Tragédia (séc. VI a.C.)

- História (séc. V a.C.)

- Comédia

(final do sec. V a.C.)

- Filosofia (séc. IV a.C.)

- Oratória (final do séc. IV a.C.)

- Fábula (séc. I d.c.)

- Teologia (séc. IV d.c.)
Odisseia, de Homero Os trabalhos e os dias, de Hesíodo Prometeu acorrentado, de Ésquilo Histórias, de Heródoto Lisístrata, de Aristófanes
A República, de Platão
Terceira Filípica, de Demóstenes Fábulas, de Fedro
A Cidade de Deus, de Agostinho

${ }^{9}$ Os gêneros clássicos são: o épico, lírico, dramático (tragédia, comédia, etc.) e o narrativo (fábula, romance, etc.). Cf. Nicola 2003: 34-39. 
$\mathrm{Na}$ abordagem das obras, apresentamos uma breve caracterização de seus aspectos históricos e literários e um roteiro de análise de temas específicos de cada obra. Esses roteiros de análise foram elaborados a partir da leitura de autores especialistas em História Antiga, mas também, e principalmente, são fruto de debates com os alunos e anotações em fichas, cadernos, elaborados de forma livre e provisória no decorrer da nossa experiência de sala de aula.

\section{TEXTO E CONTEXTO: MÉTODO DE LEITURA HISTÓRICA}

$\mathrm{Na}$ análise das obras, visando a articulação entre literatura e sociedade, não adotamos um método unificado tal como seria, por exemplo, o método histórico-formal da abordagem materialista da literatura, que consiste em pôr de um lado os aspectos sociais e de outro a sua ocorrência na obra literária, propondo uma síntese dialética que permita vislumbrar uma interpenetração efetiva do literário com o social.

Nesse livro, as nossas análises das obras escolhidas estão ainda condicionadas ao nível de reflexão da bibliografia específica dos temas, limitando-se, por vezes, a resumir as posições e métodos adotados dos pesquisadores, e, aqui e ali, tentando dar uma contribuição pessoal, própria, na interpretação.

Geralmente, o que se convencionou chamar método de leitura histórica para os historiadores é a identificação da realidade social com o "contexto" e a compreensão histórica é definida, assim, como uma função da contextualização. A leitura histórica, nessa perspectiva, representa um tipo de leitura que sobrepõe o contexto ao texto, contexto esse que é entendido como uma realidade fora do texto e não pertencente a ele. A obra literária torna-se apenas mero pano de fundo do social, sem efetiva força cognitiva.

O que se percebe nos estudos literários desde a segunda metade do século xx, é um movimento de reaproximação do texto como alterna- 
tiva para o arbítrio das interpretações "externas", "contextualistas". Esse movimento de explicação interna do texto literário revelou-se, num primeiro momento, num movimento positivo e fecundo para os estudos literários, que veio influenciar os estudos históricos de textos literários, trazendo para os historiadores a necessidade de se dar mais atenção ao texto, saber ler uma narrativa, reconhecer as regras do discurso literário. ${ }^{10}$

Essa atenção ao texto como método de análise, no entanto, não significa que o historiador abandone a busca de uma contextualização na análise das obras literárias. A noção de contexto, por outro lado, tem que ser pensada numa perspectiva relacional com o texto e, como diz Lacapra, "o julgamento e o tato requeridos para decidir quando a procura do contexto foi longe demais são dificuldades necessárias na pesquisa"11.

Para além da discussão metodológica entre texto e contexto, consideramos que é preciso dar mais autonomia à obra literária, que nem é imune aos condicionamentos sociais, nem é mero reflexo dos mesmos. Nesse sentido, procuramos em nossas análises dar mais atenção ao texto, à narração, percebendo como se constroem os sentidos. Considerar dinâmica as representações sociais (no caso a literatura), é afirmar que essas representações são ao mesmo tempo instituídas e instituintes do social. ${ }^{12}$ O texto literário é, assim, uma forma de "ação social" - ao mesmo tempo que representa o real intervém nele. ${ }^{13}$

${ }^{10}$ Starobinsky 1976.

${ }^{11}$ Lacapra 1991: 122ss.

${ }^{12}$ Para uma visão crítica da concepção de que as representações são "criadoras" do mundo social - presente na chamada História Cultural - acusando a presença de certo “idealismo" nessa concepção, ver Cardoso 2000: 10.

${ }^{13}$ Meneses 1998: 71. 


\section{CONSIDERAÇÕES FINAIS}

Como observações finais, acreditamos que essa proposta teórico-metodológica desenvolvida a partir da relação entre história e literatura para o estudo da História Antiga é proveitosa no sentido de substituir o tratamento meramente factual desse extenso conteúdo, como se encontra nos antigos manuais de história antiga e nos livros didáticos, por uma abordagem mais analítica, apresentando agora recortes temáticos e, sobretudo, uma reflexão sobre a própria construção do conhecimento histórico da antiguidade, ou seja, discutindo que tipo de antiguidade temos produzido, quais as que nos foram legadas e até mesmo a possibilidade de criar outras novas.

Nesse sentido, nosso livro didático A História Antiga a partir de textos literários - que é destinado aos alunos de graduação dos cursos superiores de ciências humanas - diz respeito a uma proposta de leitura da antiguidade que estamos construindo através de nossa atividade como professor e pesquisador, e que tem como principais objetivos: iniciar com os alunos uma reflexão sobre o processo de elaboração e produção do saber histórico; introduzir o aluno no trabalho do historiador através do contato com fontes, bibliografia específica e interpretação crítica das mesmas e, por fim, explorar o potencial da literatura enquanto objeto de construção do conhecimento histórico.

\section{BIBLIOGRAFIA}

Andrade, L. (2000), "Literatura e Ciências Sociais", Lócus, Revista de História. UFJF, 6. 2: 65-73.

Baslez, Marie-F. (2003), Les sources littéraires del'histoire grecque. Paris, Armand Colin. Bosi, A. (1986), Reflexões sobre a arte. São Paulo, Ática.

Cardoso, C. F. (1997), "História e análise de textos", In Cardoso, C.F. e Vainfas, R. Domínios da história. Rio de Janeiro, Campus, 375-399. 
- (1999), “Tinham os antigos uma literatura?”, Phoînix. UFRJ, 5: 99 - 120.

- (2000), “Uma opinião sobre as representações sociais", In Representações: contribuição a um debate transdisciplinar. Campinas, Papirus, 9-39.

Certeau, M. de (1994), "Ler: uma operação de caça", In A invenção do cotidiano. 1. Artes de fazer. Petropólis, Vozes, 259-273.

Chalhoub, S. e Pereira, L. (1998), "Apresentação", In A história contada. Capítulos de História Social da literatura no Brasil. Rio de Janeiro, Nova Fronteira, 7-13.

Compagnon, A. (2010, 2ª ed.), "O gênero como modelo de leitura", In 0 demônio da teoria, Literatura e senso comum. Belo Horizonte, UFMG, 154-156.

Ferreira, A. C. (2009), "Literatura: a fonte fecunda", In Pinsky, C. B., Luca, T. R. de (orgs.), O historiador e suas fontes. São Paulo, Contexto, 61-91.

Finley, M. I. (1994), "O estudioso da história antiga e suas fontes / Os documentos", In História Antiga: testemunhos e modelos. São Paulo, Martins Fontes, 11-62.

Funari, Pedro P. A. (1995), "Documentos: análise tradicional e hermenêutica contemporânea / Análise documental e antiguidade clássica", In Antiguidade Clássica: a história e a cultura a partir dos documentos. Campinas, Unicamp, 11-36.

Guarinello, N. L. (2013), História Antiga. São Paulo, Contexto.

Hartog, F. (2003), "História Antiga e história", In Os antigos, o passado e o presente. Brasília, UnB.

Lacapra, D. (1991), “História e o romance”, Revista de História. IFCH/ UNICAMP, 2-3: 107-124.

Meneses, U. T. B. (1998), “As marcas da leitura histórica: arte grega nos textos antigos", Manuscrítica, 7: 69-82.

Nicola, J. de (2003), “A arte / A arte literária / Os gêneros literários”, In Literatura brasileira. São Paulo, Scipione, 9-44.

Ribeiro, R. J. (1994), "O risco de uma nova ortodoxia”, Revista USP, 23: 7-13.

Sousa, P. A. de M. (2010), A História Antiga a partir de textos literários. Teresina, UFPI - Inédito. 
Starobinsky, J. (1976), “A literatura - o texto e seu intérprete”, In Le Goff, J. e Nora, P., História - Novas Abordagens. Rio de Janeiro, Francisco Alves, 132-143.

Todorov, T. (1980), "A noção de literatura/ A origem dos gêneros”, In Os gêneros do discurso. São Paulo, Martins Fontes, 11-24; 43-58.

Vieira, Maria do Pilar et al. (2002), "Os documentos - atos e testemunhos da história”, In A pesquisa em história. São Paulo, Ática, 12-28. 